\title{
An SV40 Transformation Revertant Due to a Host Mutation: Isolation and Complementation Analysis
}

\author{
GARY H. SILVERSTEIN, ${ }^{*}$ DAVID C. KOHRMAN, ${ }^{+}, 1$ JOAN B. CHRISTENSEN, $\dagger$ \\ WILLIAM W. BROCKMAN, ${ }^{*,+, 2}$ AND MICHAEL J. IMPERIALE $*,+, 3$ \\ *Graduate Program in Cellular and Molecular Biology and t Department of Microbiology and Immunology. \\ University of Michigan, Ann Arbor, Michigan 48109-0620
}

Received October 9, 1991; accepted December 23, 1991

\begin{abstract}
We have isolated an SV40 transformation revertant cell line, CL1L, by selection for normal cells whose growth is inhibited under low serum conditions. This line expresses a single, wild-type copy of large T antigen, yet is not transformed. It is not retransformable by transfection of SV4O DNA or infection with a recombinant retrovirus encoding large $T$ antigen. Resistance to transformation therefore appears to be due to a cellular mutation. Fusion of CL1L cells to normal 3T3 cells or SV40-transformed cells results in somatic cell hybrids that are transformed, indicating that resistance is recessive. In addition, fusion of CL1L cells to another SV40 transformation-resistant line, A27, results in transformed hybrids, indicating the existence of discrete complementation groups with respect to SV40 transformation. (c) 1992 Academic Press, Inc.
\end{abstract}

\section{INTRODUCTION}

The disruption of normal cell growth control by SV40 large $T$ antigen requires the interaction of $T$ antigen with proteins which normaliy regulate cell growth and division. Although some of these proteins, such as $p 53, p R b$, and p107/p120 (referred to herein as p120), have been identified and their genes cloned and characterized (Linzer and Levino, 1979; Lane and Crawford, 1979; DeCaprio et al., 1988; Ewen et al., 1989; Dyson et al., 1989), they alone cannot account for large $T$ antigen's transforming ability. For example, some mutant $T$ antigens which still bind these proteins are defective for transformation (Rutila et al., 1986; Manfredi and Prives, 1990; Yaciuk et al., 1991), and mutants which do not bind these proteins can sometimes still transform (Srinivasan et al., 1989; Tack ct al., 1989; Ludlow et al., 1990). Thus, at least one more host function must be involved in transformation. Additionally, one would like to know what steps beyond binding of $T$ antigen to host proteins lead to the trans formed state.

All of the proteins mentioned above were recognized by their presence in immunoprecipitates of $T$ antigen. While such biochemical analysis of $T$ antigen complexes is a powerful approach toward identifying such

\footnotetext{
1 Present address: Department of Human Genetics, University of Michigan Medical School, Ann Arbor, Ml 48109.

${ }^{2}$ Deceased.

${ }^{3}$ To whom reprint requests should be addressed.
}

factors, it can be limited in that it only allows detection of proteins which are stably associated with $T$ antigen. Proteins which interact with $T$ antigen on a transient basis and proteins which act downstream of those actually bound to $T$ antigen probably escape detection in these assays.

In attempts to identify these types of factors, a number of laboratories, including ours, have taken genetic approaches toward the study of transformation by $T$ antigen. Specifically, we have been interested in isolating murine cell lines which are resistant to transformation by large $T$ antigen. Such cell lines presumably contain a cellular mutation which renders them resistant. One such line, A27, was isolated by introducing T antigen into 3T3 fibroblasts under nonselective conditions and screening for cells that express $T$ antigen but are not transformed (Ryan et al., 1985). Another genetic approach involves the isolation of transformation revertants, derivatives of transformed cell lines which appear to be normal due to host mutations (Vogel et al., 1973; Maruyama et al., 1982; Bauer et al., 1987). In this report, we describe the isolation and characterization of one such revertant cell line, CL1L. CL1L cells express a functional $T$ antigen $(T+)$, are transformation negative ( $\mathrm{tr}-$ ), and are specifically resistant to retransformation by SV40. Fusion of CL1L to normal and transformed cells indicates that the defect in $C L 1 \mathrm{~L}$ is recessive. Of particular interest, fusion of $C L 1 L$ to $A 27$ yields transformed cells, indicating the existence of at least two complementation groups with respect to SV40 transformation susceptibility. 


\section{MATERIALS AND METHODS}

\section{Cell lines}

All cell lines except retrovirus producer lines were maintained in minimal Eagle's medium (MA Bioproducts) supplemented with $0.2 \mathrm{mg} / \mathrm{ml} \mathrm{NaHCO}, 0.29$ $\mathrm{mg} / \mathrm{ml}$ glutamine, 100 units $/ \mathrm{ml}$ penicillin, and $100 \mu \mathrm{g} /$ $\mathrm{ml}$ streptomycin. Transformed and revertant cells were maintained in 10\% fetal calf serum (MEM-10); and BALB/C 3T3 cells in 20\% fetal calf serum (MEM-20). Retrovirus producer cell lines (Brown et al., 1986) were maintained in Dulbecco's modified Eagle's medium (GIBCO) supplemented with 100 units $/ \mathrm{ml}$ penicillin, $100 \mu \mathrm{g} / \mathrm{ml}$ streptomycin, and 10\% calf serum (DMEM10). The transfer of dominant selectable markers into cells for use in fusion experiments was carried out by transfection of pSV2neo (Southern and Berg, 1982) or pY3 (Blochlinger and Diggelmann, 1984), followed by selection in 400 to $600 \mu \mathrm{g} / \mathrm{ml} \mathrm{G418} \mathrm{(GIBCO)} \mathrm{or} 300$ $\mu \mathrm{g} / \mathrm{ml}$ hygromycin B (CalBiochem), respectively. Wellisolated, drug-resistant colonies were picked and subcloned by end point dilution.

\section{Isolation of revertants}

To isolate serum revertants, A209R1B1 cells were plated on Day 0 at a density of $1 \times 10^{4} \mathrm{cells} / \mathrm{cm}^{2}$ in MEM-10. On Day 1 the medium was changed to $\mathrm{MEM}-1$, and on Day 2 one of two drugs was added: $200 \mu \mathrm{g} / \mathrm{ml}$ fluorodeoxyuridine (FUdR) in the presence of $2 \mathrm{mg} / \mathrm{ml}$ uridine, or $1 \mu \mathrm{g} / \mathrm{ml}$ colchicine. Excess uridine was added during FUdR treatment to prevent the incorporation of FUdR into RNA. After a 6-day exposure to the drugs, cells were trypsinized and plated in MEM10. Surviving colonies were subcloned by limiting dilution. To isolate density revertants, A209R1B1 cells were plated on Day 0 at a density of $6 \times 10^{4}$ cells $/ \mathrm{cm}^{2}$ and exposed to drugs for 3 days.

\section{Transfections}

Calcium phosphate-DNA precipitates were made and added to cells as previously described (Imperiale et al., 1983). Approximately 18 to $24 \mathrm{hr}$ later the medium containing the precipitate was removed and the cells were fed with MEM-10. After an additional $24 \mathrm{hr}$, cells were split into assays as described under Results.

\section{Transformation and growth assays}

Monolayer overgrowth assays, measurements of cell growth in 10\% FCS and 1\% FCS, and focus formation assays were performed as described (Brockman, 1978; Christensen and Brockman, 1982). Assay dishes were stained with $0.1 \%$ Wright's stain in methanol. Soft agar assays were carried out as described previously (Brockman, 1978; Christensen and Brockman, 1982), with the following modifications. Assays on the original 56 candidate revertant cell lines were performed in low-melting-point agarose (LMPA), which was used at a concentration of $0.625 \%$ in the base layer and $0.412 \%$ in the cell overlay layer. The assays were fed weekly with overlay mixture, and the dishes were scored after 2 weeks. All subsequent assays used low EEO agarose (Boehringer-Mannheim) at $0.5 \%$ in the base layer and $0.33 \%$ in the cell overlay layer. These assays were fed weekly with overlay mixture and scored after 5 weeks. Colonies were scored positive if they were $\geqslant 0.01$ inches in diameter.

\section{Southern blots}

Southern blots were performed using $0.8 \%$ agarose gels as previously described (Bender and Brockman, 1981).

\section{Plasmid DNA preparation}

Plasmid DNA was prepared by standard methods (Maniatis et al., 1982).

\section{Retroviral infections}

Twelve hours prior to infection the producer cells, at $80 \%$ confluence, were fed fresh DMEM-10. The day of the infection, the medium from the producer lines was collected, polybrene was added at $8 \mu \mathrm{g} / \mathrm{ml}$, and the mixture was passed through a $0.45-\mu \mathrm{m}$ low-proteinbinding filter. Cells at approximately $50 \%$ confluence were infected with $2 \mathrm{ml}$ of the harvested retroviral medium for $2 \mathrm{hr}$ at $37^{\circ}$ with gentle rocking every $20 \mathrm{~min}$. The dishes were then fed with $8 \mathrm{ml}$ of MEM-10, moved to $33^{\circ}$, incubated for 2 days, and split into assays. Infected cells $(1 / 1000$ or $1 / 500)$ were plated into 60 $\mathrm{mm}$ dishes in $500 \mu \mathrm{g} / \mathrm{ml} \mathrm{G418}$ to determine the efficiency of the retroviral infection. Cells to be assayed for transformation were split either $1 / 100$ or $1 / 50$ from the infected dish into 100-mm dishes and grown in MEM10 plus $500 \mu \mathrm{g} / \mathrm{ml} \mathrm{G} 418$. After 2 weeks these cells were placed into soft agar assays, picked to establish clonal cell lines, or used for immunoprecipitations. The remainder of the original dish of infected cells was placed directly into focus or $1 \%$ serum assays.

\section{Cell fusions}

The day before the fusion, equal numbers of cells from both parental lines were plated into each of three $10-\mathrm{cm}^{2}$ wells in MEM-10 at $37^{\circ}$. Fusion was carried out the next day, when the cell monolayers had reached confluence. Medium was removed and the cells were exposed to $1 \mathrm{ml}$ of $50 \% 2 \times \mathrm{MEM}, 5 \%$ FCS, 
$0.3 \mathrm{mg} / \mathrm{ml}$ glutamine, 100 units $/ \mathrm{ml}$ penicillin, $100 \mu \mathrm{g} / \mathrm{ml}$ streptomycin, and $50 \%(\mathrm{~V} / \mathrm{V})$ polyethylene glycol 600 (Sigma) for $40 \mathrm{sec}$ followed by rapid dilution with $4 \mathrm{ml}$ MFM-5. The cells were then washed four times with 2

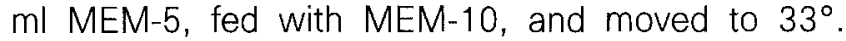
Twenty-four hours later the cells were fed with fresh MEM-10. The next day cells from the three wells were trypsinized, pooled, and plated into two $150-\mathrm{cm}^{2}$ flasks in MEM-10. The following day selection was started with $450 \mu \mathrm{g} / \mathrm{ml} \mathrm{G418}$ and $300 \mu \mathrm{g} / \mathrm{ml}$ hygromycin B. Equal numbers of surviving colonies were pooled and placed into transformation assays.

\section{Immunoprecipitation analysis}

Confluent 100-mm dishes of cells were washed once with DMEM without methionine (DMEM met-) and fed with $5 \mathrm{ml}$ of labeling medium (10\% FCS, 10\% DMEM, and $80 \%$ DMEM met-) containing ${ }^{35}$ S-labeled methionine and cysteine (Translabel, ICN Radiochemicals) at $60 \mu \mathrm{Ci} / \mathrm{ml}$. Cells were labeled at $37^{\circ}$ for $23 \mathrm{hr}$. After labeling, the cells were washed twice with icecold PBS and lysed at $4^{\circ}$ for $30 \mathrm{~min}$ in $1 \mathrm{ml}$ lysis buffer (250 mM NaCl, 0.1\% NP-40, $50 \mathrm{mM}$ HEPES, pH 7.0) (Whyte et al., 1988) containing $5 \mu \mathrm{g} / \mathrm{ml}$ each of PMSF, leupeptin, and aprotinin. The lysates were cleared by centrifugation at $16,000 \mathrm{~g}$ for $2 \mathrm{~min}$ and stored at $-70^{\circ}$. Immunoprecipitations were carried out overnight at $4^{\circ}$ in $0.5-\mathrm{ml}$ reactions containing $250 \mu$ l lysate, $250 \mu \mathrm{l}$ lysis buffer, and excess antibody. Complexes were recovered by incubating with $150 \mu$ of $6 \% \mathrm{CL}-4 \mathrm{~B}$ protein $A$-Sepharose (Pharmacia) in lysis buffer for 30 min, with rocking. Samples were washed five times with $1 \mathrm{ml}$ lysis buffer, and immunoprecipitated proteins were released by boiling and separated by electrophoresis through 8\% SDS-polyacrylamide discontinuous gels (Laemmli, 1970). Gels were fixed for $30 \mathrm{~min}$ in $30 \%$ methanol, $10 \%$ acetic acid and then treated with Amplify (Amersham) for $30 \mathrm{~min}$. After drying under vacuum at $80^{\circ}$, the gels were exposed to Kodak XAR film at $-70^{\circ}$.

\section{RESULTS}

\section{Generation and characterization of SV40 revertants}

In order to increase the chances of obtaining revertants due to mutations in cellular genes, we chose a parental transformed cell line containing multiple copies of the SV40 early region. Use of such a parental line would be expected to lower the frequency of reversion resulting from loss of $T$ antigen coding regions. This line, A209R1B1, is an SV40-transformed BALB/C 3T3 line that expresses at least two distinct transformationcompetent large T antigens (Brockman, 1978; Bender
TABLE 1

Growth Assays of Revertant Cell Lines

\begin{tabular}{lcc}
\hline Cell line & $\begin{array}{c}\text { Monolayer } \\
\text { overgrowth }\end{array}$ & $\begin{array}{c}\text { Growth in } \\
\text { soft agar }\end{array}$ \\
\hline Expt 1 & & \\
3T3 & 0.190 & 0.01 \\
A209R1B1 & 0.002 & 0.27 \\
CL1F & $<0.004$ & 0.04 \\
CL1L & & 0.08 \\
Expt 2 & - & \\
3T3 & 0.200 & 0.01 \\
A209R1B1 & $<0.002$ & 0.48 \\
CL1E & $<0.002$ & 0.03 \\
CI11B & & 0.13 \\
Expt 3 & - & \\
3T3 & 0.1 & 0.01 \\
A209R1B1 & 0.02 & 0.7 \\
FH2B & 0.025 & 0.8 \\
FH2K & & 0.1 \\
\hline
\end{tabular}

${ }^{a}$ Efficiency of plating is the number of colonies/number of cells seeded into the assay.

et al., 1983). To isolate revertants, A209R1B1 cells were subjected to the negative selection protocols discussed under Materials and Methods. These conditions allow for growth of transformed cells, which are then selectively killed by the cytotoxic drugs colchicine or FUdR. Colchicine disrupts microtubule polymerization and kills cells by inhibiting cytokinesis (Borisy and Taylor, 1967) and is more toxic to SV40-transformed cells than normal cells (Vogel et al., 1973). FUdR prevents thymidine synthesis by inhibiting thymidylate synthetase (Rueckert and Mueller, 1960). Two different selection protocols were employed with each drug in an effort to generate revertants caused by distinct cellular alterations: cells plated at high density in normal concentrations of serum, or low density in low serum, were selected with each drug.

Fifty-six potential revertant cell lines were isolated using the four variations of the selection scheme. This represents a reversion frequency of about $1 \times 10^{-5}$, which is within the range reported by others (Culp and Black, 1972; Vogel and Pollack, 1973). These cell lines were screened for the presence of large $T$ antigen by indirect immunofluorescence, the ability to overgrow preformed monolayers of BALB/C $3 T 3$ cells, and growth in LMPA. Six cell lines had the desired phenotype, $\mathrm{T}^{+} / \mathrm{tr}^{-}$. These fell into two classes: colchicine serum revertants, designated CL (Colchicine, Low density), and FUdR density revertants, designated $\mathrm{FH}$ (FUdR, High density) (Table 1). All six produce large T antigen which localizes to the nucleus. Five exhibit at least partial reversion in both growth parameters. 
$\mathrm{FH} 2 \mathrm{~B}$, however, fails to form colonies on preformed monolayers, yet grows as well as A209R1B1 in LMPA.

To examine the integrity of the early region sequences in the revertant lines, cellular DNA from these lines and A209R1B1 was digested with Hpall and $B a m H I$, enzymes which separate the early region of the SV40 genome from the late region, and analyzed by Southern blotting using a probe that consists of the entire SV40 genome. The results from four of the cell lines are shown in Fig. 1A. CL1E, CL1F, CL1L, and $\mathrm{FH} 1 \mathrm{~B}$ all contain an intact SV40 early region, as indicated by a diagnostic band of 3056 nucleotides. All of these cell lines therefore contain early region sequences that are capable of encoding a wild-type size $T$ antigen. The large $T$ antigen produced by the six cell lines was examined by immunoprecipitation of $\left.{ }^{35} \mathrm{~S}\right]$ methionine-labeled proteins with hamster antiSV40 tumor serum (Fig. 1B). All six lines produce a large $T$ antigen of $94 \mathrm{kDa}$, the same size as wild-type $\mathrm{T}$ antigen. The cellular protein p53 coimmunoprecipitates with $T$ antigen in all the revertant lines. This analysis suggests that there is no gross alteration of the $T$ antigens produced by these six cell lines.

\section{Retransformation with wild-type $T$ antigen}

Even though the large $T$ antigens expressed by these lines appear to be wild type, viral mutations could inactivate the transforming ability of $T$ antigen without altering its sizc, association with p53, or subcellular localization. To test whether these cell lines are true cellular revertants, we asked whether they could be retransformed by introducing a wild-type copy of large $T$ antigen. The revertants were cotransfected with a plasmid encoding $T$ antigen, pSVB3, and a plasmid encoding a selectable marker, pSV2neo, at a 10:1 ratio and assayed for the ability to overgrow preformed 3T3 monolayers. Cells that survived selection in G418 were plated into transformation assays. A plasmid encoding an activated c-Ha-ras gene, pFJ6.6 (Shih and Weinberg, 1982), was transfected independently to ascertain the specificity of transformation resistance of the revertants and to ask whether they are capable of exhibiting the transformed phenotype. The FH2K cell line was difficult to transfect and was dropped from the study. CLIF, FH1B, and $\mathrm{FH} 2 \mathrm{~B}$ were retransformed by $\mathrm{T}$ antigen, but CL1L and CL1E were not (Table 2). The efficiency of transfection of all the cell lines was the same, so differences in DNA uptake cannot explain the results. In addition, all of the cell lines were transformed by ras. CL1 1 and CL1E were next tested for the ability to be retransformed in a focus formation assay. Cells were cotransfected with pSV2neo and either pSVB3 or pEJ6.6 and assayed for focus formation. Both lines were transformable by ras and resistant to SV40 (data not shown). Since CL1L grew to a lower cell
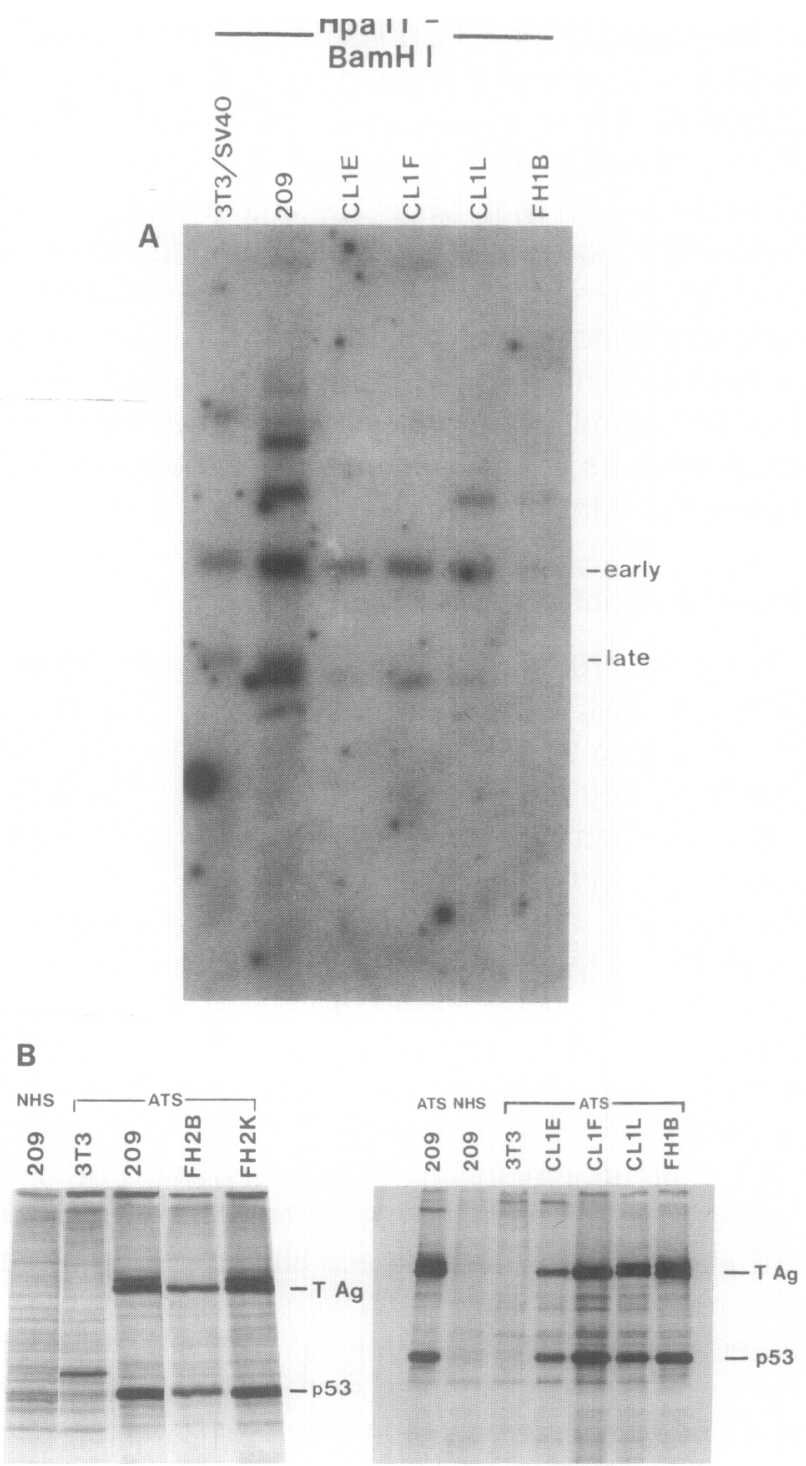

FIG. 1. Analysis of SV40 sequences and T antigen expression in reverlant cell lines. (A) Southern blot analysis. Genomic DNA from the four cell lines was digested with Hpall and BamHI, electrophoresed, and probed with the entire SV40 genome. The lane marked $3 T 3 / S V 40$ is a reconstruction in which SV40 genomic DNA was mixed with 3T3 genomic DNA and analyzed. 209 represents the A209R1B1 line. The positions of bands corresponding to the early and late regions are shown. (B) Immunoprecipitation analysis. ${ }^{35} \mathrm{~S}-\mathrm{la}-$ beled proteins were immunoprecipitated with anti-T antigen hamster ascites (ATS) or normal hamster serum (NHS) and analyzed on $8 \%$ SDS gels.

density in monolayer culture than $C L 1 F$, indicating the tightest growth control, further examination was restricted to CL1L.

\section{Growth parameters of the transformation revertant CL1L}

Additional growth parameters of the CL1L cell line were examined to determine whether other properties 
TABLE 2

Retransformation of Revertant Cell Lines

\begin{tabular}{lrr}
$\begin{array}{l}\text { Cell } \\
\text { line }\end{array}$ & Sv40 & \\
3T3 & 2.5 & ras $^{a}$ \\
CL1L & 0.1 & 1.3 \\
CL1E & $<0.1$ & 20.0 \\
CL1F & 0.6 & 1.4 \\
FH1B & 5.5 & 1.7 \\
FH2B & 0.5 & 6.0 \\
\hline
\end{tabular}

${ }^{a}$ EOP on preformed $3 T 3$ monolayers is expressed as the number of colonies/number of cells plated $\times 100$.

of CL1L had also reverted. The morphologies of confluent monolayers of A209R1B1, CL1L, and 3T3 cells are shown in Fig. 2A. A209R1B1 cells are spindleshaped, rounded, refractile, and grow in a disorganized, dense configuration that is typical of transformed cells. 3T3 cells are flat, nonrefractile, and form well-ordered monolayers. The morphology of CL1L cells is indistinguishable from that of $3 T 3$ cells. By this criterion, $C L 1 L$ is therefore classified as a revertant. As shown in Table 3, the efficiency of plating (EOP) of CL1L cells in soft agar is much more like that of $3 T 3$ cells than that of A209R1B1 cells. Photographs of representative fields of soft agar assays in Fig. 2B show colonies of $\mathrm{CL} 1 \mathrm{~L}$ cells to be slightly greater in size than colonies of 3 T 3 cells (which remained as single cells), but much smaller than the colonies of A209R1B1 cells. Even though the CL1L ccll line appears to have some capacity to form anchorage-independent colonies, this capacity is much less than that of A209R1B1 cells. Therefore, $C L 1 L$ has reverted as judged by this parameter. Saturation density in 10\% FCS and the ability to grow in $1 \%$ FCS were also examined (Table 3). Once again, CL1L cells behave like normal cclls. Since the $\mathrm{CL} 1 \mathrm{~L}$ cell line was originally isolated as a serum revertant, it is especially significant that CL $1 \mathrm{~L}$ cells do not grow in $1 \%$ serum.

\section{Characterization of the CL1L T antigen}

One possible explanation for the inability of the transfected SV40 early region to retransform CL1L is that the $\mathrm{T}$ antigen expressed by CL1L might be defective and dominant over the exogenously introduced $T$ antigen. Southern blot analysis showed that CL1L contains a single copy of the early region (data not shown), so we cloned a genomic fragment containing this copy into a plasmid vector to create pSVCL1L. This plasmid, or one expressing wild-type T antigen (pSVB3 or pJYM), was transfected into $3 \mathrm{~T} 3$ cells to assess the relative transforming ability of the CL1L T antigen. pSVCL1L transforms 3T3 cells with at least wild-type efficiency as judged by focus formation, ability to grow in soft agar, and growth in low serum (Table 4). Indeed, cells receiving the CL1L T antigen had a higher EOP in soft agar than cells that received wild-type $T$ antigen. By these three criteria, then, the CL1L-encoded large $T$ antigen appears to be a fully functional transforming protein.

\section{Transformation resistance of CL1L}

To more closely examine the transformation resistance of $C L 1 L$, we infected cells with a retrovirus expressing a large $T$ antigen cDNA to efficiently introduce T antigen into the cells (Brown et al., 1986). CL1L and $3 T 3$ cells were infected with this virus (TEXS) or a control virus lacking the $T$ antigen CDNA (SVX), and the infected cells were assayed for three growth parameters (Table 5). The TEXS virus induced anchorage-independent growth of 3 T3 cells to a significantly higher extent than it did of CL1L cells. This is most clearly seen by comparing the relative EOP of TEXS-infected cells to that of SVX-infected cells for both cell lines: the TEXS EOP:SVX EOP for $3 T 3$ cells is approximately 20 times higher than that for CL1L. In addition, the TEXS virus induced a significantly larger overall colony size in $3 T 3$ cells than it did in CL1L cells and induced many microcolonies in $3 T 3$ cells which were not scored as positive since they were smaller than colonies of uninfected CL1L cells (Fig. 3). Thus, the change in the soft agar growth phenotype of CL1L cells after TEXS infection is not as great as that observed with $3 T 3$ cells. We also examined the behavior of the infected cells in focus formation in 5 and $1 \%$ serum (Table 5). Again, the two cell lines behaved quite differently. TEXS-infected 3 T3 cells formed aggressive foci in monolayers in $5 \%$ serum which were obvious by 13 days postinfection. CL1 L cells infected with TEXS never formed foci in monolayer culture, although they did grow to a slightly higher density than SVX-infected CL1L cells. In 1\% serum, TEXS-infected 3T3 cells formed foci but at a level lower than that in 5\% serum. No growth of CL1L was observed in $1 \%$ serum after infection with either the TEXS or the SVX virus. We conclude that although soft agar growth of CL1L cells can be increased slightly by $T$ antigen, these cells are not capable of being fully retransformed.

\section{Specificity of CL1L transformation resistance}

To further define the specificity of transformation resistance, the CL1L cell line was transfected with a small panel of oncogenes: a polyoma middle $T$ antigen cDNA (pPyMT1); an activated c-Ha-ras gene (pEJ6.6); and a viral src gene (pMvsrc). Transfected cells were 

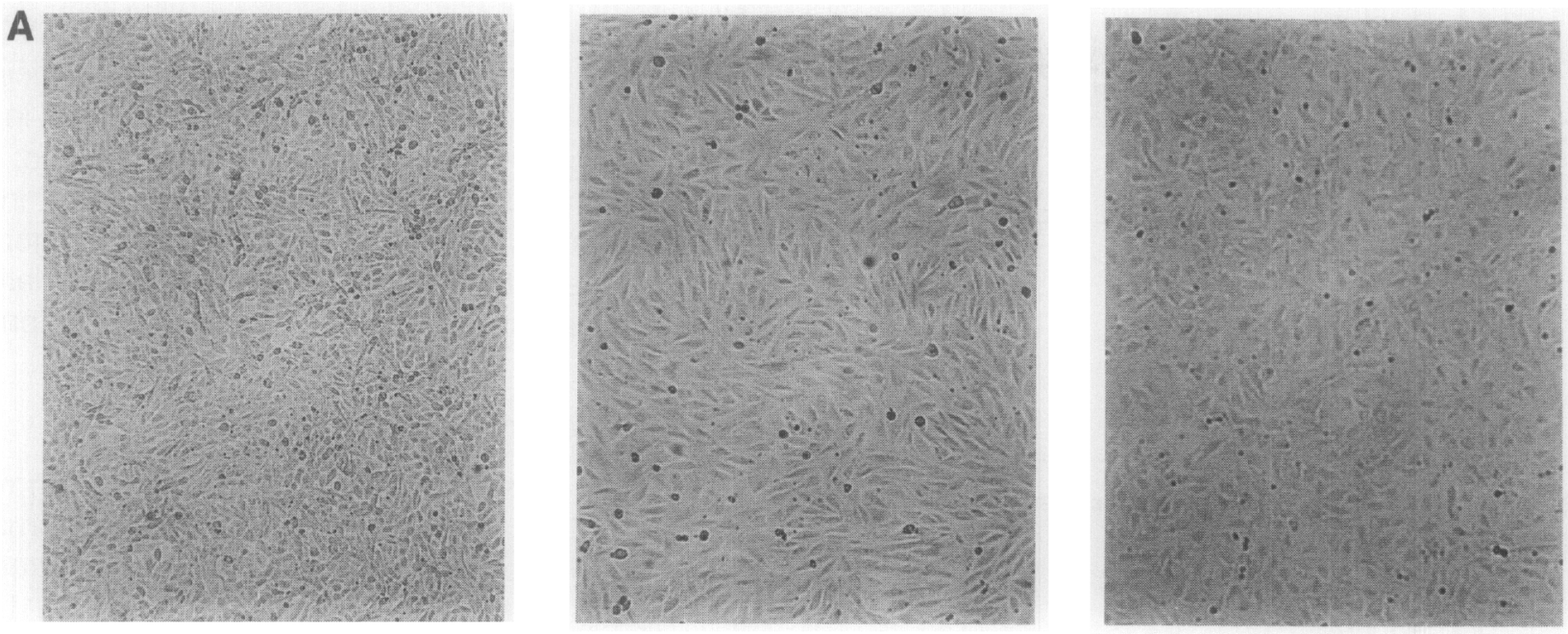

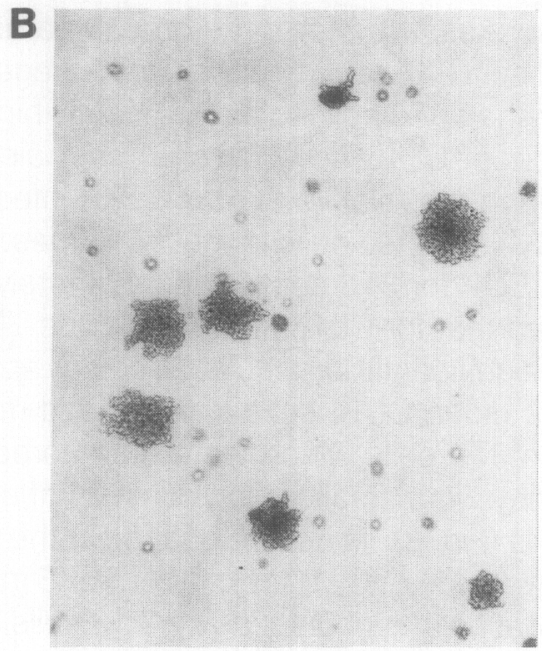

A209R1B1

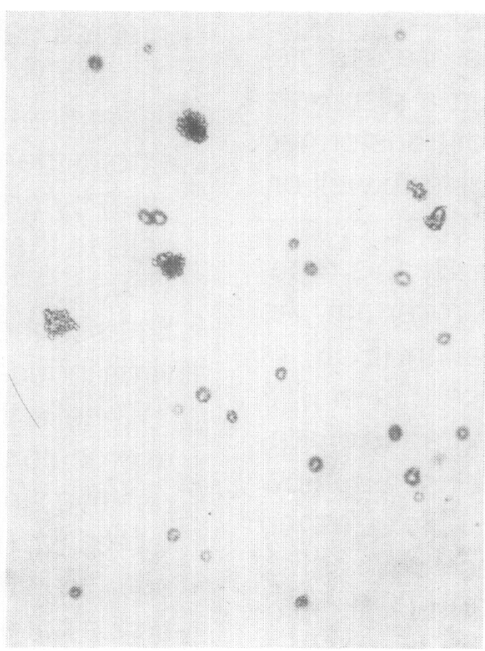

CL1L

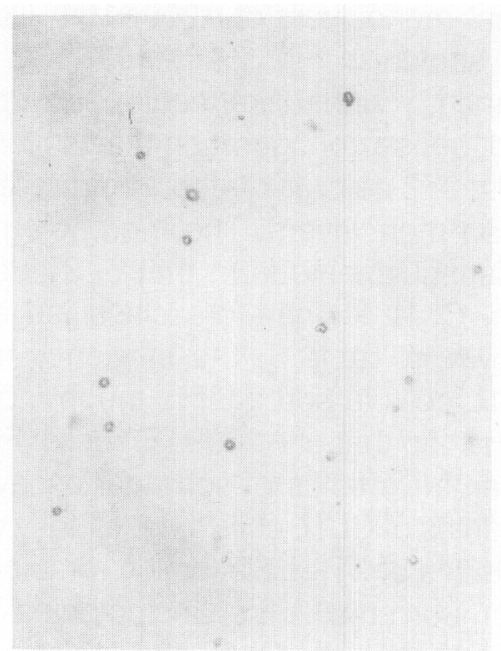

3Т3

FIG. 2. Morphology and growth of CL1L cells. (A) Photographs of confluent monolayers of cells. (B) Photographs of soft agar colonies.

assayed for growth in soft agar and focus forming ability in 5 and 1\% FCS (Table 6). All three oncogenes induced the growth of CL1L cells in soft agar. Soft agar colonies of $C L 1 L$ cells transfected with middle $T$ and v-src were quite large, showing that $C L 1 L$ can exhibit the full transformed phenotype in soft agar (Fig. 4). All of the plasmids were also able to confer focus forming ability on CL1L in 5\% serum, although to various extents: the effects on CL $1 \mathrm{~L}$ of middle $T$ antigen and ras were much greater than the effects of v-src. This difference was also seen in $1 \%$ serum assays, where middle $T$ antigen and ras induced CL1L cells to form foci, but $v$-sre did not.

\section{Binding of $\mathrm{T}$ antigen to cellular proteins in CL1L}

An obvious candidate for a cellular mutation in CL1L would be one of the $T$ antigen-binding proteins which have bcen shown to play a role in SV40 transformation. We therefore examined the cellular proteins that are bound to large $T$ antigen. CL1L cells or A209R1B1 cells were metabolically labeled and proteins were isolated, immunoprecipitated with the anti-T antigen antibody PAb4 19, and subjected to SDS-PAGE. In precipitates from both $C L 1 L$ and its parental cell line one finds p53 and a protein with an approximate molecular weight of $120 \mathrm{kDa}$ (Fig. 5). This is probably the p107/ p120 protein that binds to the $\mathrm{pRb}$ binding domain of large $T$ antigen (Ewen ct al., 1989), since a large $T$ antigen mutant in this domain does not complex with this protein and it does not comigrate with $\mathrm{pRb}$ (D.C.K. and M.J.I., in press). Although $\mathrm{pRb}$ may be present in these precipitates just above the $T$ antigen band, experiments to prove that this is the $\mathrm{Rb}$ protein were inconclusive. Nevertheless, there is no obvious defect in 
TABLE 3

Growth of CLIL in Soft Agar and Saturation Density IN $1 \%$ OR $10 \%$ SERUM

\begin{tabular}{lcrr}
\hline & & \multicolumn{2}{c}{ Saturation density ${ }^{b}$ in } \\
\cline { 3 - 4 } Cell line & $\begin{array}{c}\text { EOP in } \\
\text { soft agar }\end{array}$ & $1 \%$ Serum & $10 \%$ Serum \\
\hline A209R1B1 & $3.84(192)$ & $34.0 \times 10^{4}$ & $97 \times 10^{4}$ \\
CL1L & $0.04(2)$ & $4.4 \times 10^{4}$ & $15 \times 10^{4}$ \\
3T3 & $<0.02(0)$ & $3.9 \times 10^{4}$ & $13 \times 10^{4}$ \\
\hline
\end{tabular}

${ }^{a}$ EOP is the number of colonies/number of cells plated $\times 100$. The number in parentheses is the average number of colonies scored of 5000 cells plated per dish.

${ }^{b}$ Saturation density is the number of cells $/ \mathrm{cm}^{2}$.

binding to proteins known to be involved in SV40 transformation.

\section{The phenotype of CL1L is recessive and defines a complementation group}

To determine if the defect in CL1L is dominant or recessive, CL1L subclones expressing selectable markers were fused to normal cells (BALB/c 3T3) or to transformed cells (A209R1B1) expressing different selectable markers. Somatic cell hybrids were selected and plated into soft agar to test for anchorage-independent growth (Table 7). Fusion of CL1L to normal 3T3 cells resulted in hybrids that have a much higher EOP than either parental cell line. Some of these hybrid colonies in soft agar were larger than colonies formed by A209R1B1, indicating that these fused cells are fully transformed. Fusion of CL1L cells to transformed A209R1B1 cells also resulted in hybrids with an EOP greater than that of CL1L cells and comparable to that

TABLE 4

Transformation of BALB/C 3 T3 CELLS BY the CL1L LARge T ANTIGEN

\begin{tabular}{lccc}
\hline & & \multicolumn{2}{c}{ Foci in $^{b}$} \\
\cline { 3 - 4 } Plasmid & Soft agar $^{a}$ & $5 \%$ Serum & $1 \%$ Serum \\
\hline pSV2neo & $<0.01$ & 2 & 0 \\
pSVB3 & 0.29 & 18 & $N D$ \\
pJYM & 0.31 & ND & 25 \\
pSVCL1L & 0.53 & 18 & 24 \\
\hline
\end{tabular}

Note. The relative transfection efficiencies, as judged by the number of G418 colonies, were comparable for all samples.

${ }^{a}$ EOP is as defined in Table 3 . Value is average of two to four experiments.

${ }^{b}$ Average number of foci per $100-\mathrm{mm}$ dish ( $5 \%$ serum) or $60-\mathrm{mm}$ dish ( $1 \%$ serum) from two experiments.

TABLE 5

GROWTH OF RETROVIRAL INFECTED CELLS IN SOFt AgAR, AND FOCUS FORMATION IN $5 \%$ AND 1\% SERUM

\begin{tabular}{llcccc}
\hline & & & \multicolumn{2}{c}{ Foci in } \\
\cline { 4 - 5 } Cell line & Virus & Soft agar & $5 \%$ Serum & $1 \%$ Serum \\
\hline \multirow{2}{*}{$3 T 3$} & TEXS & 1.35 & 243 & 61 \\
\multirow{2}{*}{ CL1L } & SVX & 0.006 & 1 & 0 \\
& TEXS & 0.062 & 0.7 & 0 \\
& SVX & 0.005 & 0 & 0 \\
\hline
\end{tabular}

Note. See Table 4 for definitions. Soft agar and $5 \%$ serum values are averages of three experiments. The $1 \%$ serum assay is one experiment.

observed when $3 T 3$ cells were fused to transformed cells. The defect in CL1L could be complemented by normal cells and does not suppress the phenotype of a transformed cell; therefore, it appears to be recessive. Fusion of the CL1L cell line to another $\mathrm{T}^{+} / \mathrm{tr}^{-}$cell line, A27, was also performed to test for complementation. The EOP in soft agar of these hybrids indicates that the two cell lines complement each other (Table 7). Fusion of each cell line to itself did not result in transformation. The CL1L $\times$ A27 hybrids form soft agar colonies that are fully transformed, as judged by their size.

svx
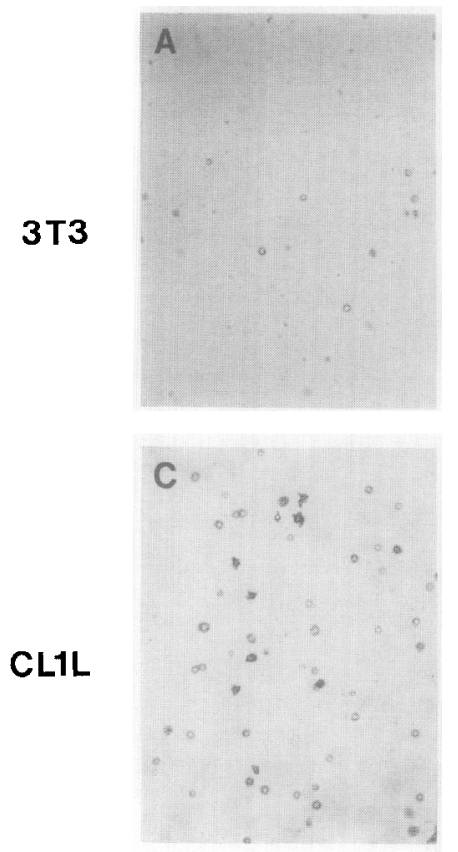

Fig. 3. Growth of retroviral-infected cells in soft agar. Soft agar colonies of (A) SVX-infected 3T3; (B) TEXS-infected 3T3; (C) SVX-infected CL1L; and (D) TEXS-infected CL1L. 
TABLE 6

Transformation of CL1L by Other Oncogenes

\begin{tabular}{lcrc} 
& & \multicolumn{2}{c}{ Foci in } \\
\cline { 3 - 4 } Plasmid & Soft agar & 5\% Serum & $1 \%$ Serum \\
\hline pSV2neo & 0.05 & 1.2 & 2.8 \\
pMvsrc & 0.34 & 29.0 & 0 \\
pEJ6.6 & 0.60 & 167.3 & 49.0 \\
pPyMT1 & 0.86 & 312.0 & 93.5 \\
\hline
\end{tabular}

Note. See Table 4 for definitions. Soft agar and $5 \%$ serum values are averages of three to four experiments. The $1 \%$ serum values represent one to two experiments.

\section{DISCUSSION}

Expression of SV40 large T antigen in nonpermissive cells triggers cell division and morphological changes through its interaction with a number of host factors and the subsequent activation or suppression of path ways controlled by these factors (Green, 1989). In the present study, we have isolated a cell line, CL1L, which appears to carry a recessive mutation in such a factor. The evidencc for such a mutation is threefold. First, CL1L expresses a T antigen which is fully capable of transforming cells, yet CL1L exhibits the growth phenotypes of a normal cell. Second, CL $1 \mathrm{~L}$ is resistant to retransformation by exogenously added large $\mathrm{T}$ antigen but not other representative oncogenes. Third, hybrids formed by fusing CL1L with either normal or transformed cells are themselves transformed. In addition, the normal phenotype is stable: rerevertants arise at a frequency of $2.5 \times 10^{-7}$, although these cells rarely grow as aggressively as the parental cell line, A209R1B1, when plated in soft agar.

We examined the function of the $T$ antigen expressed in CL1L by cloning out the single SV40 early region from $C L 1 L$ and testing its ability to transform 3T3 fibroblasts. We have extensively mapped the SV40 sequences in CL1L and find no evidence for a second copy of any part of the early region. Thus, it appears that one of the two copies of the early region originally present in A209R1B1, the parental cell line, was lost during isolation of CL1L. Nonetheless, the CL1L T antigen transforms at least as well as wild-type $T$ antigen on a molar basis. Although the level of $T$ antigen in CL1L is less than that expressed in A209R1B1, it is more than sufficient to transform 3T3 cells (G.H.S., $\mathrm{Ph}$.D. thesis). In addition, the fact that fusion of $\mathrm{CL} 1 \mathrm{~L}$ cells to $3 T 3$ cells yields transformed hybrids indicates that the CL1L T antigen is fully functional. Finally, $C L 1 L$ $T$ antigen is fully capable of forming complexes with $p 53$ and $p 120$. Detection of $T$ antigen-pRb complexes in rodent cells has been technically difficult, even in cells expressing very high levels of T antigen, in a number of laboratories including our own (J.B.C., unpublished data). We do not think, however, that the defect in $C L 1 L$ involves $p R b$, for the following reasons. We know that the $T$ antigen in $C L 1 L$ can bind $p R b$ since it can transform normal cells (Table 4). Thus, one would have to argue that the $\mathrm{pRb}$ in CL1L is mutated such that it blocks cell growth and is unresponsive to $T$ antigen. If this were the case, one would expect this unresponsive $\mathrm{pRb}$ to be dominant over wild-type $\mathrm{pRb}$,

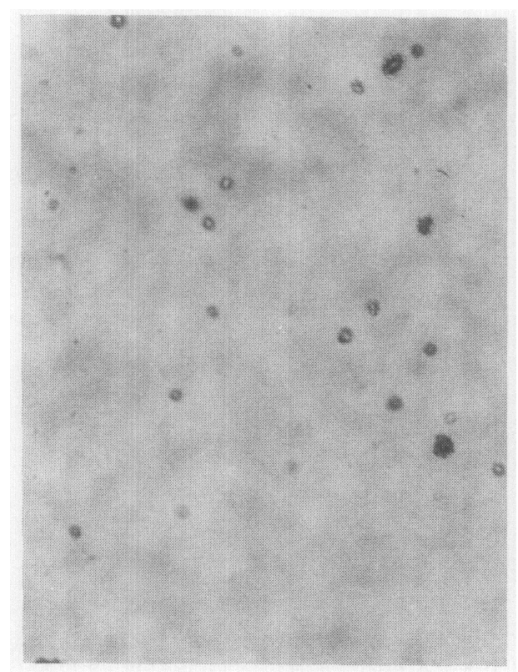

neo

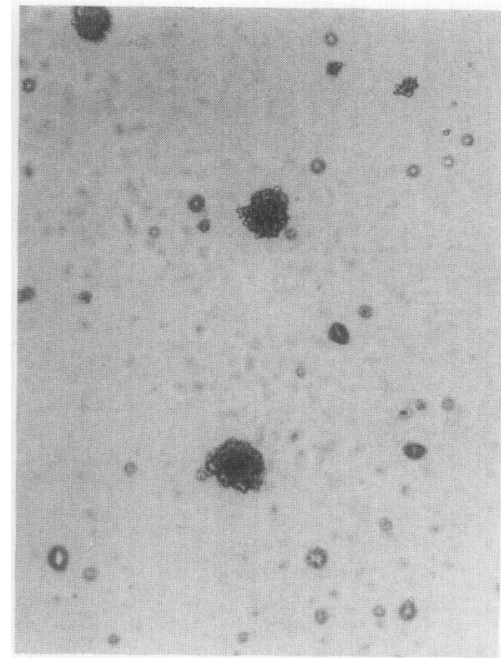

PyMT

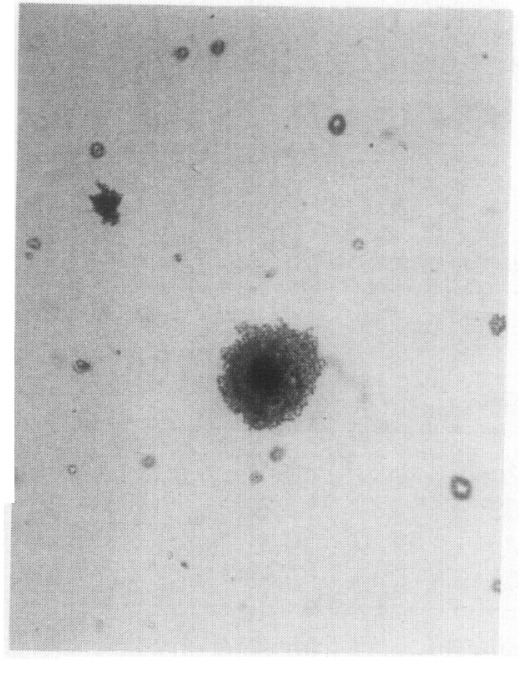

v-src

Fig. 4. Soft agar growth of oncogene-transfected CL1L cells. Colonies of cells transfected with control plasmid (neo), polyomavirus middle $T$ antigen (PyMT), or V-src are shown. 


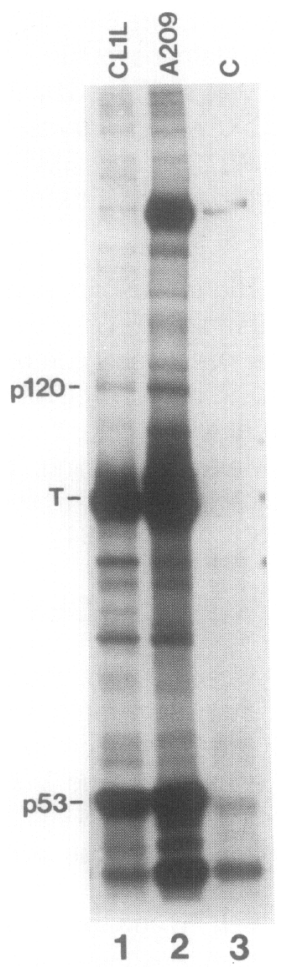

FIG. 5. T antigen-binding proteins in CL1L cells. ${ }^{35} \mathrm{~S}$-labeled proteins from: lane 1, CL1L immunoprecipitated with PAb419; lane 2, A209R1B1 with pAB419; lane 3, A209R1B1 with C2-5, an isotypematched control monoclonal specific for herpes simplex virus type 2 glycoprotein $\mathrm{C}$. The high-molecular-weight band in lane 2 is a nonspecific band sometimes seen in A209 precipitates.

which is presumably inactivated when it is bound to $T$ antigen (Buchkovich et al., 1989; DeCaprio et al., 1989). Our data, however, show that fusion of CL1L to normal cells, which express wild-type $\mathrm{pRb}$, results in transformation (Table 7). Although this does not formally rule out a mutation in the $\mathrm{Rb}$ gene in $\mathrm{CL} 1 \mathrm{~L}$, the possibility of such a mutation is clearly inconsistent with current available data. Since evidence does exist for an additional host function in SV40 transformation (Rutila et al., 1986; Manfredi and Prives, 1990; Yaciuk et al., 1991; Michael-Michalovitz et al., 1991), it is possible that the mutation in CL1L may define the gene encoding that function.

When exogenous $T$ antigen is introduced into $\mathrm{CL} 1 \mathrm{~L}$ by infection with a recombinant retrovirus, growth in soft agar is stimulated somewhat, and the cells grow to a higher density in monolayers. These retroviral-infected cells do not, however, form soft agar colonies as large as those tormed by infected 3T3 cells, nor do they form foci in monolayers or grow in low serum. This indicates that the mutation in CL $1 \mathrm{~L}$ differentially affects these three parameters of the transformed state, namely anchorage independence, loss of contact inhibition, and serum independence. In addition, the intro- duction of exogenous $T$ antigen appears to have an effect upon anchorage-independent growth, but the infected cells do not form large colonies in soft agar, presumably due to the cellular mutation. One possible explanation for this is that $T$ antigen might play two roles in transformation: (1) stimulating progression through the cell cycle and (2) inducing expression of the characteristic transformation phenotypes. In this model the presence of additional $T$ antigen in $\mathrm{CL} 1 \mathrm{~L}$ might stimulate extra rounds of division but not allow the full phenotypic changes which define the transformed state, perhaps as occurs in abortive transformation. A prediction of this model is that other agents which stimulate cell division might have the same effect.

The finding that the normal growth phenotype of $C L 1 L$ is recessive opens the possibility of identifying the gene involved by standard DNA transfection protocols: genomic DNA or CDNA expression libraries from transformation-competent cells should be able to complement the defect. Although this type of analysis requires single-gene defects, the frequency at which $\mathrm{CL} 1 \mathrm{~L}$ arose, approximately $10^{-5}$, indicates that the involvement of more than one gene is unlikely. Moreover, although such a frequency appears high for a recessive mutation, one must remember that the parental cells, being transformed, have likely suffered extensive chromosomal loss and rearrangement and may therefore be haploid at many loci. Since the phenotype of CL1L is most striking in low serum, such conditions should provide a powerful selection in a complementation assay.

\section{TABLE 7}

Growth IN Soft Agar of Somatic Cell Hybrids

\begin{tabular}{ll}
\multicolumn{1}{c}{ Cells } & EOP \\
\hline A209Hym1A & 0.98 \\
CL1LNeo & 0.03 \\
3T3Hym4 & 0.01 \\
3T3Neo & 0.01 \\
A27SVX2 & 0.01 \\
A209Neo $\times$ A209Hym1A & 0.76 \\
CL1LHym X CL1LNeo & 0.02 \\
A27Hym1B XA27SVX2 & 0.01 \\
CL1LNeo $\times$ 3T3Hym4 & 0.28 \\
CL1LNeo X A209Hym1A & 0.40 \\
3T3Neo $\times$ A209Hym1A & 0.70 \\
CL1LHym $\times$ A27SVX2 & 0.53 \\
\hline
\end{tabular}

Note. EOP is the number of soft agar colonies/number of cells plated $\times 100$. The drug resistance of each cell line is indicated by the suffixes Hym and Neo for hygromycin and G418 resistance, respectively. A27SVX2 is also G418 resistant. 
A number of groups have studied cell lines in which the expression of SV40 T antigen does not correlate with the growth phenotype, due to a cellular mutation. Pollack and co-workers previously described a number of revertant cell lines (Pollack et al., 1968; Vogel and Pollack, 1973; Vogel et al., 1973; Vogel and Pollack, 1974), as did Maruyama et al. (1982). At that time, however, tools for molecular analysis were unavailable. More recently, the Graessmann group has identified a revertant line, Rev2, which appears to be due to a recessive mutation (Bauer et al., 1987). Studies on tsA $\mathrm{N}$-type and A-type transformants, cells expressing a temperature-sensitive $T$ antigen which do and do not return, respectively, to a normal growth phenotype when grown at the nonpermissive temperature, indicate that the phosphorylation pattern of $T$ antigen correlates with the growth phenotype (Knippschild et al., 1991). Specifically, it was found that return to growth control was accompanied by a shift to an underphosphorylated form of T antigen in the $\mathrm{N}$-type cells at the nonpermissive temperature, whereas the $\mathrm{T}$ antigen in the A-type cells retained the same phosphorylation pattern at both temperatures. This may be significant in that it appears that this same underphosphorylated form of T antigen has recently been found in Rev2 cells (Deppert et al., 1991). It will therefore be of interest to examine the phosphorylation of $\mathrm{T}$ antigen in $\mathrm{CL} 1 \mathrm{~L}$ cells.

The most provocative result of these studies is the complementation of the $\mathrm{CL} 1 \mathrm{~L}$ and $\mathrm{A} 27$ cell lines. This indicates that the defects in these two transformationresistant lines fall into separate complementation groups. Since A27 cells were isolated under nonselective conditions and therefore were never transformed, whereas $C L 1 L$ is a transformation revertant, it is possible that the two cell lines harbor independent mutations in genes which affect, respectively, establishment and maintenance of the transformed state. Alternatively, the two defects may relate to the two functions proposed for $T$ antigen above. It would be interesting to test other revertants in complementation assays to obtain an idea of how many host functions might be involved in transformation by SV40. The further study of transformation-resistant cell lines such as CL1L and A27 should provide valuable information about the pathways involved in SV40-mediated transformation.

\section{ACKNOWLEDGMENTS}

\footnotetext{
The authors thank David Livingston for recombinant retroviruses and encouragement; Bob Weinberg, Bill Folk, Svend Freytag, and David Shalloway for plasmids; Karen Dolter, and especially Ed Harlow, for monoclonal antibodies; and the members of our lab for their intellectual and technical help in this project. We also acknowledge
}

the input of Stuart Sweet and Laura Elenich in the early stages of this project. M.J.I. thanks Dan Nathans for his encouragement to pursue these studies. This work was supported by Grant No. CA 19816 from the NIH. G.H.S. and D.C.K. were supported in part by NIH Predoctoral Training Grants GM07315 and GM07544, respectively, and M.J.I. is supported in part by Faculty Research Award FRA-338 from the American Cancer Society.

Note added in proof. The manuscript referred to as D. C. K. and M. J. I., in press, is Kohrman, D. C. and Imperiale, M. J. (1992). Simian Virus 40 large $T$ antigen stably complexes with a 185 -kilodalton host protein, $J$. Virol., in press. A cDNA encoding $p 107$ has recently been cloned: Ewen, M. E., Xing, Y., Lawrence, J. B., and Livingston, D. M. (1991) Molecular cloning, chromosomal mapping, and expression of the cDNA for p107, a retinoblastoma gene product-related protein. Cel/ 66, 1155-1164.

\section{REFERENCES}

Bauer, M., Guhl, E., Graessmann, M., and Graessmann, A. (1987). Cellular mutation mediates T-antigen-positive revertant cells resistant to simian virus 40 transformation but not to retransformation by polyomavirus and adenovirus type 2. J. Virol. 61, 1821-1827.

BENDER, M. A., and BROCKMAN, W. W. (1981). Rearrangement of integrated viral DNA sequences in mouse cells transformed by simian virus 40 . J. Virol. $38,872-879$.

Bender, M. A., Chiristensen, J, and Brockman, W. W. (1983). Characterization of a T-antigen-negative revertant isolated from a mouse cell line which undergoes rearrangement of integrated sim. ian virus 40 DNA. J. Virol. 47, 115-124.

Blochlinger, K., and DiggelmanN, H. (1984). Hygromycin B phosphotransferase as a selectable marker for DNA transler experiments with higher eucaryotic cells. Mol. Cell. Biol. 4, 2929-2931.

BoRISY, G. G., and TAYLOR, E. W. (1967). The mechanism of action of colchicine: Binding of colchicine ${ }^{3} \mathrm{H}$ to cellular protein. J. Cell Biol. 34, 525-533.

BROCKMAN, W. W. (1978). Transformation of BALB/C-3T3 cells by tsA mutants of simian virus 40: Temperature sensitivity of the transformed phenotype and retransformation by wild-type virus. J. Virol. 25, 860-870.

Brown, M., McCormack, M., Zinn, K. G., Farrell, M. P., Bikel, I., and LivingSTON, D. M. (1986). A recombinant murine retrovirus for simian virus 40 large $T$ CDNA transforms mouse fibroblasts to anchorage-independent growth. J. Virol. 60, 290-293.

BUCHKOVICH, K., DUFFY, L. A., and HARLOW, E. (1989). The retinoblastoma protein is phosphorylated during specific phases of the cell cycle. Cel/ 58, 1097-1105.

CHRISTENSEN, J. B., and BROCKMAN, W. W. (1982). Effects of large and small T antigens on DNA synthesis and cell division in simian virus 40-transformed BALB/C 3T3 cells. J. Virol. 44, 574-585.

CIJLP, I . A., and BI ACK, P. H. (1972). Contact-inhibited revertant cell lines isolated from simian virus 40-transformed cells. 3. Concanavalin A-selected revertant cells. J. Virol. 9, 611-620.

DeCaprio, J. A., Ludlow, J. W., Figge, J., SheW, J. Y., Huang, C. M., LeE, W. H., MARSilio, E., PAUChA, E., and Livingston, D. M. (1988). SV10 large tumor antigen forms a specific complex with the product of the retinoblastoma susceptibility gene. Cel/ 54, 275-283.

DeCAPRIO, J. A., LudLoW, J. W., LYNCH, D., FurukaWA, Y., GrifFin, J., PIWNiCA-WORMs, H., HuANG, C. M., and Livingston, D. M. (1989). The product of the retinoblastoma susceptibility gene has properties of a cell cycle regulatory element. Cel/ 58, 1085-1095.

Deppert, W., Kurth, M., Graessmann, M., Graessmann, A., and KNIPPSCHILD, U. (1991). Altered phosphorylation at specific sites confers a mutant phenotype to SV 40 wild-type large T antigen in a flat revertant of SV40-transformed cells. Oncogene 6, 1931-1938. 
Dyson, N., BuchKovich, K., Whyte, P., and Harlow, E. (1989). The cellular $107 \mathrm{~K}$ protein that binds to adenovirus $\mathrm{E} 1 \mathrm{~A}$ also associates with the large $T$ antigens of $S V 40$ and JC virus. Cel/ 58, 249-255.

Ewen, M. E., Ludlow, J. W., Marsilio, E., DeCaprio, J. A., Millikan, R. C., Cheng, S. H., Paucha, E., and Livingston, D. M. (1989). An $\mathrm{N}$-terminal transformation-governing sequence of SV40 large $T$ antigen contributes to the binding of both $\mathrm{p} 110 \mathrm{Rb}$ and a second cellular protein, p120. Cell 58, 257-267.

GREEN, M. R. (1989). When the products of oncogenes and anti-oncogenes meet. Cell $56,1-3$.

IMPERIALE, M. J., FeldMAN, L. T., and Nevins, J. R. (1983). Activation of gene expression by adenovirus and herpesvirus regulatory genes acting in trans and by a cis-acting adenovirus enhancer element. Cell 35, 127-136.

KNIPPSChILD, U., KiefER, J., PATSCHINSKY, T., and DePPERT, W. (1991). Phenotype-specific phosphorylation of simian virus 40 tsA mutant large $\mathrm{T}$ antigens in tsA N-type and A-type transformants. J. Virol. $65,4414-4423$.

LAEMMLI, U. K. (1970). Cleavage of structural proteins during the assembly of the head of bacteriophage T4. Nature 227, 680-685.

LANE, D. P., and CRAWFORD, L. V. (1979). T antigen is bound to a host protein in SV40-transformed cells. Nature 278, 261-263.

LINZER, D. I., and LEVINE, A. J. (1979). Characterization of a $54 \mathrm{~K}$ dalton cellular SV40 tumor antigen prosent in SV4O-transformed cells and uninfected embryonal carcinoma cells. Cell 17, 43-52.

Ludlow, J. W., SHON, J., PIPAS, J. M., Livingston, D. M., and DeCAPRIO, J. A. (1990). The retinoblastoma susceptibility gene product undergoes cell cycle-dependent dephosphorylation and binding to and release from SV40 large T. Cell 60, 387-396.

Manfredi, J. J., and Prives, C. (1990). Binding of p53 and p105-RB is not sufficient for oncogenic transformation by a hybrid polyomavirus-simian virus 40 large $T$ antigen. J. Virol. 64, 5250-5259.

Maniatis, T., Fritsch, E. F., and Sambrook, J. (1982). "Molecular Cloning: A Laboratory Manual." Cold Spring Harbor Laboratory, Cold Spring Harbor, NY.

Maruyama, K., Furuta, T., Ueda, K., and Oda, K. (1982). Properties of $T$ antigen-positive phenotypic revertants isolated from SV4Otransformed rat and mouse cells. Microbiol. Immunol. 26, 31-40.

Michael-Michalovitz, D., Yehiely, F., Gottlieb, t., and Uren, M. (1991). Simian virus 40 can overcome the antiproliferative effect of wild-type $p 53$ in the absence of stable large $T$ antigen-p53 binding. J. Virol. 65, 4160-4168.

Pollack, R. E., Green, H., and Todaro, G. J. (1968). Growth control in cultured cells: Selection of sublines with increased sensitivity to contact inhibition and decreased tumor-producing ability. Proc. Natl. Acad. Sci. USA 60, 126-133.
RueCKERT, R., and MUeller, G. (1960). Studies on unbalanced growth in tissue culture. I. Induction and consequences of thymidine deficiency. Cancer Res. 20, 1584-1591.

RUTILA, J. E., IMPERIALE, M. J., and BROCKMAN, W. W. (1986). Replicalion and transformation functions of in vilro-generaled simian virus 40 large $T$ antigen mutants. J. Virol. 58, 526-535.

Ryan, K. W., Christensen, J. B., Imperiale, M. J., and Brockman, W. W. (1985). Isolation of a simian virus 40 T-antigen-positive, transformation-resistant cell line by indirect selection. Mol. Cell. Biol. 5, 3577-3582.

SHIH, C., and WEINBERG, R. A. (1982). Isolation of a transforming sequence from a human bladder carcinoma cell linc. Co/l29, 161 169.

SOUTHERN, P. J., and BERG, P. (1982). Transformation of mammalian cells to antibiotic resistance with a bacterial gene under control of the SV40 early region promoter. J. Mol. Appl. Genet. 1, 327-341.

Skinivasan, A., PEden, K. W., and PIPAS, J. M. (1989). The large tumor antigen of simian virus 40 encodes at least two distinct transforming functions. I. Virol. 63, 5459-5463.

Tack, L. C., Cartwright, C. A., Wright, J. H., Eckhart, W., Peden, K. W., SRInIVASAN, A., and PIPAS, J. M. (1989). Properties of a simian virus 40 mutant $T$ antigen substituted in the hydrophobic region: Defective ATPase and oligomerization activities and altered phosphorylation accompany an inability to complex with cellular p53. J. Virol. 63, 3362-3367.

VOGEL, A., and POLLACK, R. (1973). Isolation and characterization of revertant cell lines. IV. Direct selection of serum-revertant sublines of SV40-transformed 3T3 mouse cells. J. Cell Physiol. 82, 189198.

VOGEL, A., and POLLACK, R. (1974). Isolation and characterization of revertant cell lines. VI. Susceptibility of revertants to retransformation by simian virus 40 and murine sarcoma virus. J. Virol. 14, 1404-1410.

VOGEL, A., RISSER, R., and POLLACK, R. (1973). Isolation and characterization of revertant cell lines. 3. Isolation of density-revertants of SV40-transformed 3T3 cells using colchicine. 1. Cell Physiol. 82 , 181-188.

WhYTE, P., BuCHKOVICH, K. J., HOROWITZ, J. M., FrIEND, S. H., RAYBuck, M., WeinBerg, R. A., and Harlow, E. (1988). Association between an oncogene and an anti-oncogene: The adenovirus E1A proteins bind to the retinoblastoma gene product. Nature 334 , 124-129.

Yaciuk, P., Carter, M. C., Pipas, J. M., and Moran, E. (1991). Simian virus 40 large-T antigen expresses a biological activity complementary to the p300-associated transforming function of the adenovirus E1A gene products. Mol. Cell. Biol. 11, 2116 2124. 